\title{
Undermining the social foundations: the impact of colonisation on the traditional family structure of the Goulburn tribes
}

\author{
Margaret Taylor, David Schmitt and Parimal Roy
}

The family ${ }^{1}$ provided the essential foundations and structural framework for traditional $^{2}$ Aboriginal society. The nuclear family provided the foundations that were reinforced by the collective alliances and land-holdings of the extended family. Kinship, and hence family, 'was the real basis of tribal organisation'. 'The elementary or nuclear family' ${ }^{4}$ was 'the basic unit of everyday social living' ${ }^{5}$ and consisted 'of a man and his wife or wives, and their children, own or adopted' ${ }^{6}$ Clark, drawing on Curr's study of the Goulburn River Protectorate Station between 1840 and 1853, suggests the salience of this concept to the present study when he states that in traditional Aboriginal society in the region ' $[\mathrm{t}]$ he rule of patrilocality ... [decreed] ... that a married woman

1. We acknowledge the complexities of the traditional Aboriginal social structure and the consequent difficulties associated with the use of the concept 'family', and in particular 'nuclear family' with all its specific Eurocentric connotations. Birdsall (1987: 130-131) addresses some of the specific difficulties associated with their application. In spite of the anthropological looseness of these concepts, Berndt and Berndt (1977), Berndt, Berndt and Stanton (1993) and Tilbrook (1986) use them, and we consider that thinking in terms of nuclear and extended families helps to distinguish between real, traditional, and fundamental familial divisions. More importantly, for this study, we feel that they offer a useful vantage point for assessing particular social impacts of European colonisation. We argue that using kinship groups or descent groups and their various divisions instead of family and its two broad divisions would lead us into an area that is extremely confused in our primary sources, and would mean exploring a level of kinship complexity that Lawlor (1991: 242), drawing on Claude Levi-Strauss, claimed 'would demand the most complex nonlinear formulas and equations - and even they might not suffice!' We do not wish to do this, nor would our sources enable it. Finally, we feel that the 'scientific' classifications tend to dehumanise the Aboriginal people and we therefore prefer terminology that emphasises the human dimension of the tragedy.

2. In this paper, we use the term 'traditional' as a synonym for pre-contact. We do not use it to suggest, or claim, a complete disjunction between the past and the present. Aspects of the traditional continue to this day (see, for example, James Weiner 2002 regarding the persistence of habitus).

3. Abbie 1969: 193.

4. Berndt and Berndt 1977: 88.

5. Berndt and Berndt 1977: 43.

6. Thompson 1983: 11. 
resides with her husband' ${ }^{7}$ In this context, the 'conjugal unit' or 'marital unit' ${ }^{8}$ was the nuclear family of pre-colonial Aboriginal society and provided the basis for survival. The extended family - tribes, moieties and clans ${ }^{9}$ - provided the fundamental kinship and hence social structure of traditional Aboriginal society. Aspects of this structure did survive colonisation and Barwick has claimed that 'to be Aboriginal is to be born to, to belong to, to be loyal to family' ${ }^{10}$ Similarly, Daylight and Johnstone suggested postcontact continuities when, in the 1980s, they stated that 'Aboriginal values, beliefs, identity and language are developed and nurtured within the family'. ${ }^{11}$

Society and family were - and remain - indivisible within the kinship system: neither function adequately without the other. In the pre-contact period, neighbouring extended families were connected through marriage. Any assault, whether direct or indirect, on the nuclear and extended family and on the institution of marriage threatened the viability of that traditional society. In her study of south-west Australia, Tilbrook notes that at its best the traditional family unit was quite a fragile and vulnerable institution because it consisted of 'a host of individuals with different but overlapping, and potentially conflicting, alliances based on membership of different marriage categories' ${ }^{12}$ This was also to prove true in the Goulburn region, where European colonisation inadvertently exploited these tensions, with catastrophic consequences for the Aboriginal people. Colonisation impacted on the social foundations of traditional society by creating and aggravating generational and gender tensions. The resultant bitter conflict around these divisions eroded the cooperation and trust essential to the viability of the nuclear and extended family. As a consequence, as colonisation proceeded Aboriginal families in contact with European people became increasingly dysfunctional through the premature death of many women and through the economic and social marginalisation of those who remained. Competition from European males for the remaining women compounded this process and frustrated family formation. The killing of infants of AboriginalEuropean parentage further exacerbated the chaotic spiral of inter-gender conflict and familial disintegration.

This paper focuses exclusively on the nature and impact of changes in family structure among the communities of the Goulburn tribes of Victoria during the early period of colonisation. It does not provide a definitive history of the traditional Aboriginal family from initial contact to the present. We argue that the severe disruption of the nuclear and extended family was a common tragedy among the Goulburn tribes and played a significant part in the weakening of their traditional society. In general terms, the nature of the European challenge to Aboriginal society in the mid-19th century was consistent wherever it occurred and as a consequence tended to unfold in broadly similar ways; Edward Curr, a 19th-century observer of the frontier conflict, suggested that the process was broadly similar wherever it occurred. ${ }^{13}$ Therefore, where we consider it appropriate, this paper draws on material from the examination of other regions, or

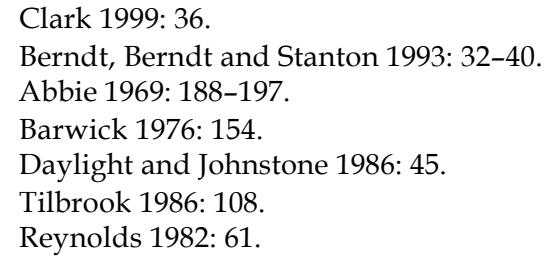


from generalised studies, to enhance or clarify the understanding of this human tragedy in the Goulbourn region. In the Goulburn region, the European settlers, administrators, and visitors in the region recorded this sorry chapter. The views they presented are Eurocentric and therefore distorted. These sources also fail to account adequately for the destruction wrought by the preceding invisible invasion - smallpox - on traditional culture. Therefore the views they present may, at best, represent a distorted picture of an already distorted traditional culture. This paper relies heavily on an analysis of what these problematic sources say and imply about family disruption. Despite the real limitations of this approach it does provide indirect access to an important, if not key, aspect of the disruption of traditional Aboriginal society.

\section{The Goulburn tribes}

The designation 'the Goulburn tribes' was a European label based on geography that was indiscriminately applied in the mid-19th century to the peoples who frequented the Goulburn River (or Central) Station of the North Eastern Protectorate in the district of Port Phillip. Only a relatively small number of the Aboriginal people of the region regularly attended the station and these were mainly drawn from the tribes of the Bangerang (or Yorta Yorta) nation, the various clans of the Ngooraialum speaking peoples, and the northern communities of the Tauounurong people. ${ }^{14}$ In 1843, a nongovernment report signed by LaTrobe noted that while 400 Aboriginal people frequented the station there were some 1000 living in 'accessible' tribes, and a further 3000 living 'beyond these limits to the north' ${ }^{15}$ The Assistant Protectorate for the Goulburn District was nominally responsible for the welfare of all Indigenous people residing east of the Campaspe and Coliban Rivers, north of the foothills of the Great Dividing Range, and south of the Murray River. In times of fear and hardship, the Goulburn River Station was visited by the people who traditionally held land between the Murray and Murrumbidgee rivers ${ }^{16}$ and, in similar circumstances, the Goulburn tribes frequented the Loddon River Station. ${ }^{17}$ The label 'the Goulburn tribes' is therefore a very imprecise designation that embraces a wide range of family and tribal groupings.

\section{The initial assault on the traditional family}

The disruption of the nuclear and extended families of the Goulburn tribes began long before the Europeans commenced their occupation of the region in the mid-1830s. Smallpox, introduced into Australia after permanent British settlement in NSW, swept through the vulnerable Aboriginal people of south-eastern Australia. ${ }^{18}$ The pre-contact Goulburn

14. We have adopted throughout this paper the practice of using the spellings of tribal and clan designations as they commonly appeared in the primary sources examined for the paper. These spellings are, in a number of cases, still used by parts of the local community today. For more recent variants, see Clark 1999: 7, 22-25.

15. Report of the Port Phillip District Committee of the Societies for Promoting Christian Knowledge 1843: 2.

16. Clark 1999: 82, 93, 100, 106, 145, 160.

17. Clark 1999: 91

18. We are aware of the debates concerning the source of these epidemics and whether they were actually smallpox. On the basis of the various arguments and evidence we tend to accept many of the central propositions espoused by Butlin (1983) where he concludes that the epidemics were smallpox and that they originated from the settled areas of Australia. 
tribes had no natural immunity to smallpox and evidence indicates they were devastated by two epidemics, the first in approximately 1800 and the second in $1830 .{ }^{19}$

It is impossible to know the number of separate Aboriginal communities that were affected by this invisible European invasion or how many lives were lost because of it. Early European observations and records of anecdotal evidence indicate epidemics were responsible for a considerable depopulation of the region. ${ }^{20}$ The people who died from smallpox did so in great numbers and suffered a horrific death. Other exotic diseases also preceded colonisation and Butlin believes the presence of these diseases would have inhibited the ability of the Aboriginal people to respond adequately to smallpox. ${ }^{21}$

In the traditional context, sorcery was seen as the agent responsible for disease. As a consequence, smallpox engendered in the survivors a level of fear and distrust of others, especially strangers. This distrust, during the early phase of colonisation, disrupted tribal affiliations and prompted an unprecedented bout of revenge killings. ${ }^{22}$ Previously friendly tribes found themselves constantly at war with each other. Dredge claimed that by 1839 the clans on the middle reaches of the Goulburn River, although from the same linguistic groups, had become implacable enemies and could barely communicate with each other. ${ }^{23}$ This intertribal conflict compounded the consequences flowing from the disruption of betrothal, marriage, and kinship lines caused by the many premature deaths from smallpox. The 1830 epidemic came at a time when traditional society was just recovering from the impact of the earlier epidemic and continued the disruption of an already weakened and vulnerable society. Sturt's descriptions of the impact of the disease in the region in the mid-1830s provided first hand evidence of the significant, and in some locations, almost total destruction of human life. While camped near the Goulburn River some two miles from its junction with the Murray River, Sturt noted that '[i]t is evident that a terrible mortality had swept them [the Bangerang peoples] in numbers away' and he deduced from the numbers and the condition of the graves that it was an 'unusual fatality' ${ }^{24}$ 'From whatever cause, death had been busy with them'. ${ }^{25}$ Colonisation was therefore the third blow in 30 years to fall on this freshly disrupted and severely compromised society. It was the blow that the traditional nuclear and extended family, and hence traditional Aboriginal society, could not survive without significant adaptations.

Throughout the 1840s discrete Aboriginal communities responded individually to the impact of settlement. Each faced the accompanying challenges alone. Whole family groups moved from the Goulburn region to the Murray and beyond to avoid the impact of European settlement. ${ }^{26}$ These people often combined to form larger communities that maintained their discrete tribal identities. Despite the survival of these tribal affiliations into the present, the new communities were not immune to the impact of

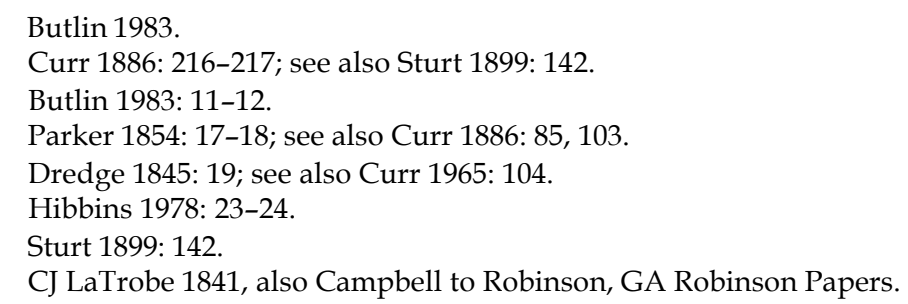


colonisation. ${ }^{27}$ Marriage and kinship lines were disrupted right across the region because of the specific impact of colonisation. Key impacts included the disruption of the nutritional and economic bases of traditional society.

\section{Undermining the nutritional and economic base of the traditional family}

The traditional Aboriginal family was essentially a self-sustaining food production unit. Tilbrook notes of south-western Australia that 'nuclear-based families hunted and foraged on land in which individual members held access and usage rights' ${ }^{28}$ This was a pattern that was common to the rest of the continent. The structure of the family and its relationship to its land ensured survival. Locality and family were and remain the 'essential bonds ${ }^{29}$ of Aboriginal society. ${ }^{30}$ Tilbrook claims that 'traditionally marriage was both the instrumentality of inheritance and the means of groups of kin gaining access to land owned by other like groups' ${ }^{31}$ Anything that undermined traditional marriage patterns and competed with a nuclear or extended family or separated it from its land directly challenged the rationale for family formation and the survival of its members.

The first permanent European settlers arrived in the Goulburn river region during a devastating drought. Traditional food, water, and medicinal resources were already severely depleted. As settler numbers increased the tribes found it increasingly difficult to compete with them and their grazing stock for these same scarce resources. ${ }^{32}$ Many Aboriginal people suffered malnutrition and faced starvation. In 1839, Dredge wrote of the people at the Goulburn River Station that:

to satisfy their hunger I have known them to eat the putrid flesh of a sheep which have been drowned for a fortnight, the stench of which was so offensive as almost to taint the atmosphere. ${ }^{33}$

As a consequence, some of the Goulburn communities fought desperately to retain their land and its precious resources.

The 'Faithful Massacre' was the first recorded armed collision between the region's Indigenous people and the Europeans. This was fought near present-day Benalla on the Broken River on 11 April 1838. Seven Europeans and an unknown number of Aboriginal people were killed. ${ }^{34}$ William Pitt Faithful later ascribed the attack to a lack of kangaroos in the area, which he believed to be related to a general distressed state among the Aboriginal people. ${ }^{35}$ Other Aboriginal people opted to trespass on neighbouring lands rather than fight the Europeans. This choice entailed breaking traditional law and was punishable by death. It also fostered inter-tribal and inter-family conflict and killings. ${ }^{36}$

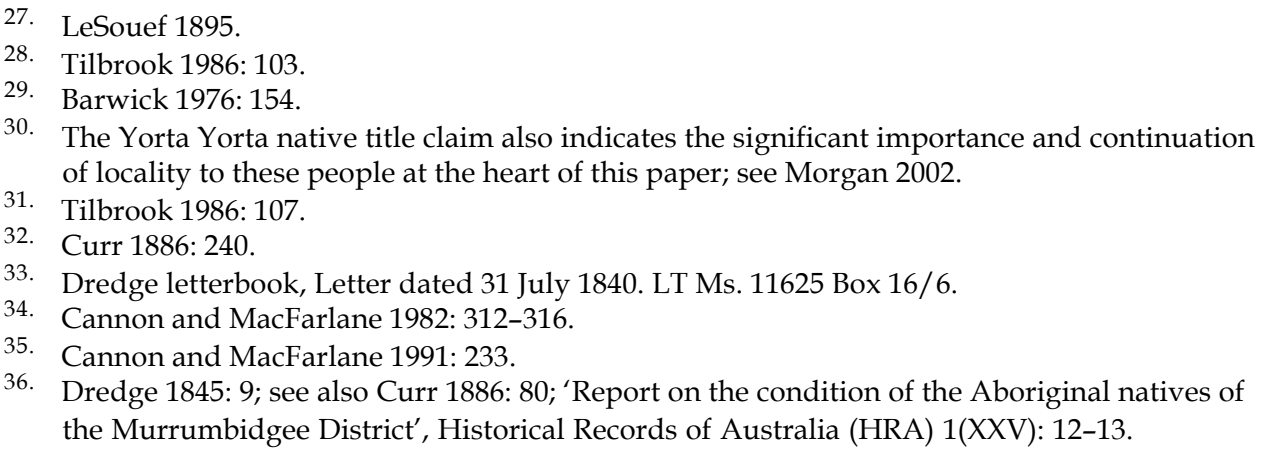


By the mid-1840s the traditional food resources of the Aboriginal communities whose land was now within the settled regions of the Port Phillip District were so depleted that McCombie claimed in 1845 that it was common for the Aboriginal people to boil and eat gum leaves for food. ${ }^{37}$ Apart from generating Aboriginal-European conflict and killings, the catastrophic loss of resources that followed European settlement also divided the generations and disrupted the traditional roles of men and women. This division and disruption was accompanied by uncharacteristic levels of intra-family violence that threatened the survival of the traditional structures supporting the extended and nuclear family.

\section{Generational divisions}

Generational divisions arose from the preferential employment of young Indigenous adults in the European colonial system and the removal of Indigenous children by private citizens and the colonial administrators. The emerging inter-generational tensions were further exacerbated by a growing dependence on introduced food and addictive substances: tobacco, sugar, tea and, later, alcohol. All of these were introduced into the tribal camps in the settled areas of the region during the $1830 \mathrm{~s}$ and $1840 \mathrm{~s} .{ }^{38}$ Broome highlights the general impact of these imports when he states that 'alcohol had disastrous effects on tribal and family life ... [leading] ... to ill-health and death.' ${ }^{39}$ In general, '[t]he lure of food was only outmatched by a desire for stimulants'. ${ }^{40}$ The use of intoxicants was not alien to traditional Aboriginal people but access and use had been limited by regulation, scarcity, and the need to secure food. ${ }^{41}$ Broome claims that out of curiosity and the promise of easy food 'many Aboriginals came in to obtain European tucker well before the traditional foods in the area were exhausted' ${ }^{42}$ This opened the way for the creation of inter-generational divisions.

In the Goulburn River region the Aboriginal people attracted to the squatting runs received addictive substances as part-payment for their labour. Whole communities chose to modify their nomadic lifestyle in order to have access to addictive stimulants. This increased their dependence on the easily acquired but nutritionally poor European food. In 1841, Curr noted a constant craving for tobacco among the neighbouring Bangerang people, who stayed close to him as their only supplier. He believed this craving to be responsible for the initial breakdown of their traditional society. ${ }^{43}$ This ensnared them in a cycle of dependence, creating a captive reserve labour force for the squatters. ${ }^{44}$ The squatters preferred to utilise the young men from this reserve labour force.

The preferential employment of young Aboriginal men by the squatters exposed them to the influences of the European culture and increased the distance between them and their communities and traditional culture. This generated and exacerbated

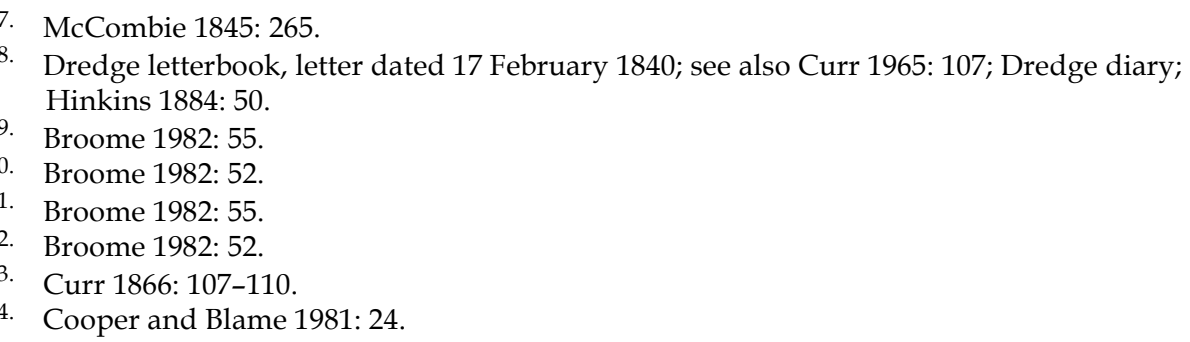


existing generational divisions within the tribes. ${ }^{45}$ The young men quickly adapted to living and working within the European economic community and it was noted that, as the 1840s progressed, many exhibited considerable fear of their tribal elders and preferred to live on the squatters' runs. ${ }^{46}$ Broome suggests the young 'were less steeped in their own culture, and thus had less to lose and possibly more to gain from the European presence' ${ }^{47}$ The tribal elders, on the other hand, vigorously resisted the alienation of their land and rightly feared the influence exerted by the Europeans over the younger generations. ${ }^{48}$ Broome claims that 'there is some evidence that young men used the upheavals created by white contact in various ways to gain women and power traditionally monopolised by the old men' ${ }^{49}$ These actions struck at traditional marriage practices and at the extended family. In January 1842 LaTrobe informed the Colonial Secretary of this generational conflict in the Goulbourn region and claimed that these young people were in danger and needed protection from their tribal communities. ${ }^{50}$

Generational and gender divisions were also promoted when Europeans, both private citizens and colonial administrators, removed Aboriginal children from their communities, alienating them from their families and tribes. ${ }^{51}$ In 1840 , Captain George Grey noted the particular pressures on Aboriginal children, more specifically the girls, who were taught the European ways only to be returned to the bush at puberty and forced to marry men raised in the traditional manner. ${ }^{52}$ Education in traditional Aboriginal society was a life-long experience and the education of these girls was incomplete. This led to misunderstandings between the men and women as well as between the generations. These misunderstandings struck directly at the foundations of the nuclear and extended family, a situation that was compounded by a number of factors that divided Aboriginal men and women.

\section{Gender divisions}

Gender cooperation was fundamental to the survival of the traditional Aboriginal nuclear family. Male and female roles were defined within the context of the family and were based on a division of labour that defined a state of relative equality. The impact of the continued and accelerating destruction of traditional resources fell heaviest upon the roles and power of the women. Hallam, in a study of the Aboriginal women of the Perth region noted that:

45. The squatters employed the young men for stock work, sheep washing and shepherding, for stripping bark for use as building materials, and for the clearing and ploughing of small areas of land.

46. 'Report on the condition of the Aboriginal Natives of the Murrumbidgee District', January 1 1847, HRA I(XXV): 560.

47. Broome 1982: 63 .

48. 'Report on the condition of the Aboriginal Natives of the Murrumbidgee District', January 1 1847, HRA I (XXV): 560.

49. Broome 1982: 63.

50. LaTrobe Correspondence with GA Robinson, 1842-1848, LT Ms. 58431 Box 650/17.

51. Hinkins, for example, took an Aboriginal child to live in his home as companionship for his daughter (Hinkins 1884: 17).

52. George Grey, Report dated 8 October, 1840, HRA I(XXI): 35. 
European fences, sheep crops and guns ... deprived Aboriginal women of access to their land to which they held rights and the carbohydrate staples they used to harvest there. The women were still expected to be the providers, but within a decade the Europeans had become the resource from which they had to harvest. ${ }^{53}$

In the Goulburn region this process changed the relationship between men and women in eight ways. First, the importance of the women's secret-sacred ceremonies waned. Women lost their inheritance of song and dance as their resources of plants, herbs and small animals were destroyed and the associated ceremonies of increase ceased to be relevant to the community. ${ }^{54}$ Ellis and Barwick also noted this outcome when writing of the song knowledge of the Antikirinja women of South Australia. They stated that 'with the availability of ready-ground flour, there may no longer be the same need to perform ceremonies for the increase of certain grass-seed species' ${ }^{55}$ The loss of their ceremonial role saw women increasingly marginalised as agents of traditional culture.

Second, women were important providers for themselves, their husbands, and their children. ${ }^{56}$ Their own economic independence and capacity to fulfil their designated role as key provider for the nuclear family depended on access to a wide range of resources, which were destroyed by the grazing practices of the settlers. The women of the Goulburn tribes, for example, relied on access to reeds from which they constructed intricate baskets and nets for their personal use. These woven items were essential tools in the tasks of procuring and transporting the family's food. The reed beds essential for their production were soon destroyed by the indiscriminate firing of the squatters. ${ }^{57}$ This severely compromised the women's capacity to trade and service their personal needs, further marginalising them within the new economic and social structures. It also undermined the traditional independence of women, ${ }^{58}$ making them increasingly dependent on Aboriginal and European males. This emerging dependence was increased by the imposition of a patriarchal social order under the Protectorate system.

Third, the imposition of European values through the allocation of food and clothing under the Protectorate system further eroded women's power. Traditionally the women were economically self-sufficient and were the primary providers for their young children. Hallam claims that in the Aboriginal society in the Perth region:

Aboriginal women ... provided their families with the basic carbohydrate staples which comprised the bulk of their diet, and the small protein supplements ... which together gave their families adequate nutrition. ${ }^{59}$

Under the Protectorate system in Victoria, the issue of rations was tied to work performed, and work was only offered to the men. It was erroneously assumed, based on the European cultural model, that men would accept responsibility for their wives and children. The allocated rations were barely sufficient for a single man, were of limited nutritional value, and did not replicate the varied and highly nutritious traditional

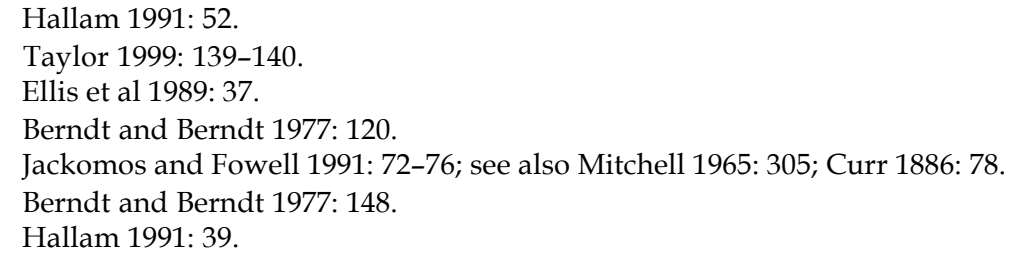


diet of Aboriginal people. ${ }^{60}$ The Aboriginal people were expected to supplement the rations with traditional food. This was unrealistic because the tribes were encouraged to stay close to the Protector and the traditional resources in the immediate vicinity were rapidly over-utilised and destroyed. As a consequence, the women and children starved. ${ }^{61}$ Assistant Protector Dredge was so distressed by the plight of the women in the Goulburn region that he created work specifically for them to supply them with food and so ease their hunger. ${ }^{62}$ While this provided immediate assistance, in the long term it served to increase the dependence of the women on the Protectorate system and on Europeans generally.

Fourth, the allocation of clothing under the Protectorate system further compromised the traditional role of women. One set of clothing and one blanket was allocated to each man, and one gown to each woman. ${ }^{63}$ In traditional society, possum skin rugs were manufactured by the men who then passed them on to the women and children. ${ }^{64}$ The lifestyle changes encouraged by the Protectorate system led to a rapid decrease in the numbers of available possums in the vicinity of the station and a corresponding decrease in the supply of rugs. Many rugs that were made were kept by the men for their own use or for barter with the Europeans. ${ }^{65}$ In this context, the plight of the women and children was compounded by the nature of the traditional nuclear family. An Aboriginal man was allowed more than one wife and may have several dependent children. The allocation of one blanket per family was totally inadequate and the women were forced to wear European-style gowns that increased their susceptibility to illness. Neither the blankets nor gowns provided the warmth or protection afforded by traditional skin rugs. The voluminous skirts did not dry easily once wet and the women could remain trapped in damp clothing for lengthy periods of time. Traditionally, the women often swam while hunting and gathering food, which was impeded by European clothing. ${ }^{66}$ While most removed the gowns when away from the Protectorate station, their health was still compromised because they lacked their traditional rugs to compensate. This also struck at their capacity to fulfil their independent cultural role. At certain times of the year, the women established their own camps in order to carry out secret-sacred business. ${ }^{67}$ This became more difficult when they were forced to depend on their husbands' camps for warmth.

Fifth, the exclusion of Aboriginal women from legitimate work in the European economic system ${ }^{68}$ further diminished their power. By the 1840s, their survival depended on gaining access to this system. The only avenue open to them was the provision of a service or product required by the European men. During the period of initial contact it was common for the tribes to offer the sexual favours of the women to

60. Dredge letterbook, Letter 3, dated 31 July 1840; see also Dredge diary, entry dated 2 June 1840.

61. Dredge diary, Latrobe Library MS 5244, Box 16/4.

62. Dredge diary, entry dated 4 June 1840.

63. Thomas to Robinson, correspondence dated 21 September 1840, GA Robinson Papers.

64. Curr 1883: 326-327.

65. Dredge diary, entry dated 18 October, 1839.

66. Pitts 1914: 17.

67. See Matthews 1905: 114-119 for a discussion of the role of the women's camp in the initiation ceremonies of the young men of the Goulburn tribes.

68. Dredge diary, entry dated June 41840. 
the settlers. This 'was a traditional way of creating friendliness, obligations and thus repayments between kin, or established good relations between groups in potential conflict' ${ }^{69}$ The practice had ceased in the Goulburn region by the 1840s, and women were rarely offered freely. ${ }^{70}$ Broome states that the one great need that bachelor Europeans had on a frontier devoid of white women was the sexual and domestic service of Aboriginal women'. ${ }^{71}$ Sometimes, when a tribe was in desperate straits in the Goulburn region, the whole community acknowledged this trade and the men acted as brokers between the women and the Europeans. ${ }^{72}$ By the 1840 s, however, many of the women in the Goulburn region were acting independently of their fathers and husbands and the younger women had found that trading in sexual favours provided their only access to the colonial economy. ${ }^{73}$ This angered the men and the ensuing conflict forced many women to leave their traditional communities. Numbers of women moved to camps on the squatters' runs where they became further alienated from their families and communities.

The number of Aboriginal women who, either by circumstances or force, cohabited with European men in the 1840s is unknown; however, in November 1850, one settler expressed the opinion that it would be difficult to find a single Aboriginal woman living in the communities within a 50 mile radius of Melbourne or Geelong who had not at some time co-habited with a European man. ${ }^{74}$ These women were vulnerable to abuse from both Aboriginal and European men. They were also victims of introduced venereal diseases which spread throughout the Aboriginal communities as both groups of men used the women caught in the middle. ${ }^{75}$ It was alleged that in the 1840s two-thirds of the Port Phillip Aboriginal people were infected by venereal diseases. ${ }^{76}$ All of these factors had dire consequences for the formation and survival of the nuclear and extended family.

Sixth, cash wages paid by the squatters to the Aboriginal men further shifted the balance of power in the communities away from an equal partnership between men and women to male dominance. It is not known when the local Aboriginal men began using English coins as a medium of exchange, however it is known that English coins were occasionally used by the male elders of the Goulburn tribes when purchasing flour in the latter months of $1839 .{ }^{77}$ English coins were reported to be in circulation freely among the Goulburn tribes by the late 1840s, when Curr observed their use in an exchange in a Bangerang community. In this instance coins were offered by one man to purchase the wife of another so she could be punished for suspected sorcery practised against the son of the first. ${ }^{78}$ The woman was subsequently put to death. ${ }^{79}$ Tilbrook

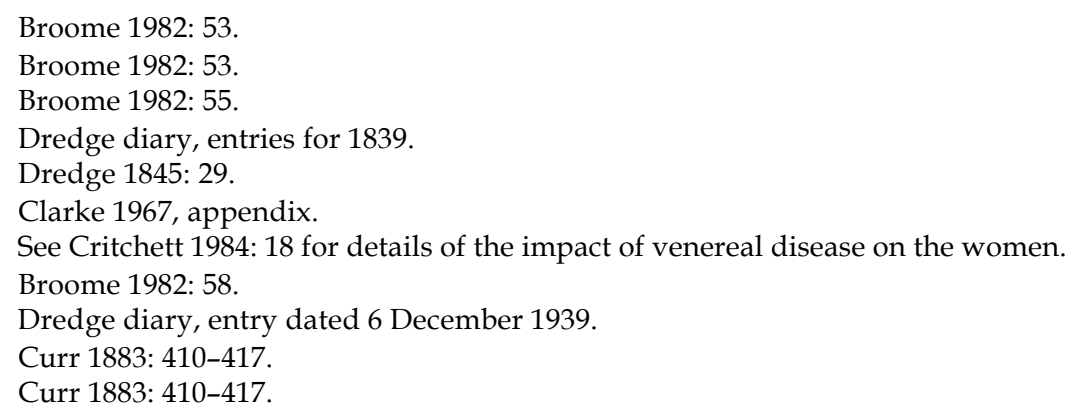


claims that European observers in south-western Australia depicted women as 'the objects of retribution in chains of retaliatory actions'. ${ }^{80}$ The Bangerang example supports this and highlights the growing importance of money and the significant devaluation of women, family, and marriage in the face of colonisation.

Seventh, infanticide, traditionally a method of population control primarily used when the survival of the community was at risk, increased in the wake of colonisation. Traditionally, the decision was made by the father of the infant, and under these circumstances the mother usually had young children and was unable to care for the new baby. ${ }^{81}$ Curr believed that traditionally, approximately half of all Bangerang infants were put to death at birth. He further observed that after the arrival of the settlers this number increased to include all children of Aboriginal-European parentage. ${ }^{82}$ Blainey argues that in traditional society it was a widespread practise to kill babies 'believed to have been fathered illegitimately'. ${ }^{83}$ The increase in infanticide noted by Curr could therefore have been provoked by the illegitimate status of the newborn of mixed parentage as well as the severe resource constraints, both of which followed in the wake of European occupation. In the 1850s, Thomas noted that among several communities, including the Goulburn tribes, 'few infants are born among them, and if born are seldom seen after the first month' ${ }^{84}$ Many of these children were of Aboriginal-European parentage, typically with an Aboriginal mother. Until the mid-1840s Aboriginal men refused to allow these children to live. ${ }^{85}$ As a consequence, women who wished to keep their children were forced to protect them at all times. ${ }^{86}$ For many the only option was to leave their community and live in camps close to the squatters' huts. This further undermined the traditional family and family formation and increased inter-gender conflict by setting men and women in direct opposition.

Eighth, the distress and frustration experienced by the disintegrating tribal communities led to an increase in the amount and severity of violence directed against women by some of the men. ${ }^{87}$ Sexual frustration and conflict over infanticide were probably key factors in this violence. Anecdotal evidence suggests that this inter-gender violence was neither traditional nor accepted behaviour. Dredge noted the outrage with which the women met the violence, and the shame exhibited by the men after it occurred. ${ }^{88}$ Parker believed that the very hard life experience by the women of the Goulburn and Loddon tribes during the 1840s and 1850s, and the violence to which they were subjected, contributed to a much shorter lifespan than that of Aboriginal

80. Tilbrook 1986: 99.

81. LeSouef (1895: 12) recalled watching Tatambo's wife killing her second daughter at the Goulburn River Station. The reason he gave was that she could not cope with two dependent infants. Her first daughter, Jinny, was three years old. See also Blainey 1988: 98.

82. Curr 1965 1883: 116.

83. Blainey 1988: 98.

84. Thomas Report dated 30 June 1853. (William Thomas was Assistant Protector at Westernport and later Protector of Aborigines in then Port Phillip District after the closure of the Protectorate System.)

85. Thomas Report dated 30 June 1853.

86. Gipps to Stanley, HRA I(XXI): 745. These babies were at risk in isolated communities until the end of the century. See Clements 1947: 2.

87. Curr 1886, vol. I: 61,100 .

88. Dredge diary, entries dated 20 December 1839, 3 February 1840, 3 March 1840. 
men. ${ }^{89}$ All these factors struck directly at the survival of the family, a situation that was exacerbated by the disruption of family formation.

\section{Disruption of family formation}

The alienation of the young men and women from the tribal communities damaged the complex traditional marriage system which dictated that each person could only take a spouse from within a carefully delineated group within the tribal society. Tilbrook notes:

Traditionally, marriage was both the instrumentality of inheritance and the means of groups of kin gaining access to land owned by other groups. Strictly enforced rules for marriage cut across territorial divisions and place people into various categories but not with all categories. ${ }^{90}$

The high mortality rate meant that large numbers of spouses promised in childhood were no longer available for marriage. An 1852 estimate of the Indigenous population for the Murray District (the boundaries of which were much the same as those of the former North Eastern Protectorate) suggested that there was a ratio of one woman to every three to four men and one child to every two women or six to eight men. ${ }^{91}$ This imbalance was exacerbated by the large numbers of young women who were forced to live on squatting runs away from their communities in an attempt to regain their economic and social independence or to escape the excessive violence, directed at them or their children, within the family unit. ${ }^{92}$ McCombie observed in the 1840 s that the relationships between the men and women were very fraught, with much fighting between men over spouses. ${ }^{93}$ Many men were left without access to wives, and by the 1850 s those women who remained within their communities had become a valuable commodity and found their freedom severely constrained.

The responses of men of marriageable age differed according to their circumstances. Some chose to ignore tribal law and steal women from other communities. ${ }^{94}$ Many murders occurred as a result of these raids and associated revenge attacks and were commonplace until 1855. In 1855 Thomas reported that murder within the tribes was no longer necessarily over women as it had been 'in former years'. ${ }^{95}$ Others, attempting to live within the constraints of their traditional law, formed homosexual liaisons when appropriate spouses were unavailable. Robinson, in response to Dr Baylie's report on homosexuality at the Goulburn River Station, stated his belief that these were isolated instances and that the practise was not usual among Aboriginal men but has resulted, in his opinion, from exposure to the behaviour of some Europeans. ${ }^{96}$

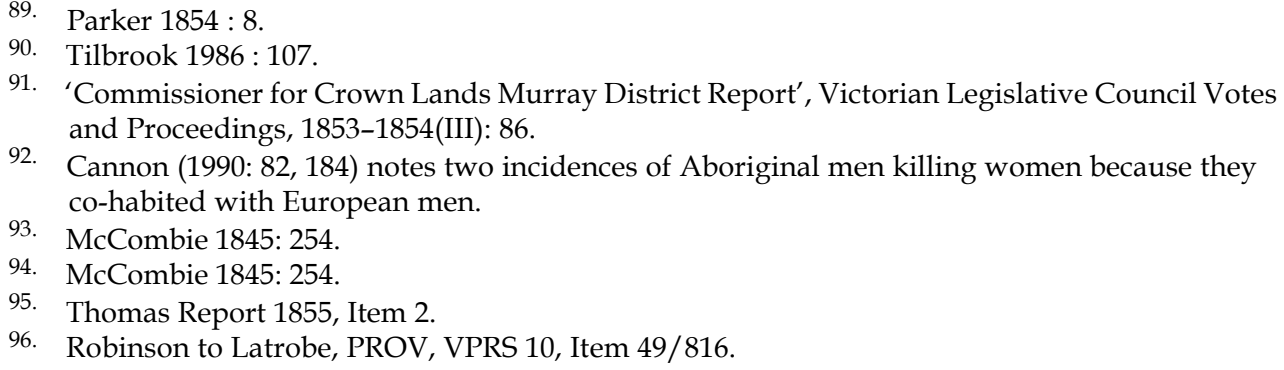


Beveridge observed that the only Aboriginal men along the Murray who maintained the stability afforded by the family were those who lived with their wives well away from the larger tribal communities. ${ }^{97}$ Ironically, this represented the triumph of the nuclear over the extended family and the complete reversal of the traditional situation in which the extended family complemented and ensured the survival of the nuclear family. For others, the lack of appropriate spouses left Aboriginal men without a traditional family. This completed their total alienation from their traditional land and society and they wandered in large groups throughout the region. ${ }^{98}$ These groups were the most obvious outcome of the disruption of the nuclear and extended family, the significant distortion of the gender ratio in the Aboriginal population, and the erosion of traditional marriage practices. Colonisation was largely responsible for a society of families being replaced by a rootless, predominantly male, remnant with little hope of re-establishment in its original form. In the face of the significant loss of the family many resorted to alcohol. Alcohol addiction and abuse became common among the Goulburn communities during the late 1840s and many deaths occurred because of drunken behaviour. ${ }^{99}$ But despite this sorry outcome a nucleus of people did survive to ensure a continuous presence in their traditional locality.

\section{Conclusion}

The nuclear and extended families of the Goulburn tribes in the years between the arrival of smallpox and the coming of the Europeans were tense institutions riven by cross-cutting loyalties and the potential for inter-generational and gender conflict. The massive depopulation caused by the invisible invasions of introduced smallpox generated inter-tribal conflict, disrupted traditional marriage practices and interfered with nuclear family formation. The visible invasion of colonisation followed hard on the heels of the invisible invasions of disease and opened up the generation and gender divisions. Colonisation alienated Aboriginal people from their land and resources, challenging the very foundations of the traditional nuclear and extended family, while conflict between the generally adaptive young and their resistant elders directly challenged its viability. The viability of the nuclear family was challenged by European competition for Aboriginal women and by the increasing alienation of women from men through a restructuring of traditional gender roles, violence, the impact of venereal disease, conflict over infanticide, and the significant decrease in the fertility and number of Aboriginal women. With the nuclear and extended family in tatters, little of substance remained to ensure the survival of traditional society. The erosion of the family unit and the accompanying disruption of the marriage system contributed enormously to the restlessness, melancholy, and depression experienced by Aboriginal people and observed so frequently during the 1840s that Europeans came to believe these to be characteristic of the Indigenous peoples generally. ${ }^{100}$ The fact that some via-

\footnotetext{
97. Beveridge 1889: 12.

98. Henry Bingham Commisioner for Crown Lands, Murrumbidgee District, to Colonial Secretary Thomson 1845, 'Report on the Murrimbidgee District', dated 26 December, 1845, HRA I(XXV): 11; see also Robinson Papers, correspondence dated 12 April 1840; also Robinson Report, PROV VPRS 10, Item 47/1185.

99. Thomas Report 1855

100. McCombie 1845: 257-258.
} 
ble remnants of families and kinship networks did survive to ensure continuity to the present day bears testimony to their intrinsic attachment to their land and the adaptability of the people who remained.

\section{Acknowledgement}

We are very grateful to the members of the Aboriginal community in the Goulburn Valley for their generous support and encouragement throughout the study. We extend our sincere thanks to them.

\section{References}

\section{Primary sources}

Aboriginal Protectorate Reports and Records, Public Record Office Victoria, PROV VPRS 10.

Clarke, H 1967, 'Notes of Thomas (Dreweatt) Clarke of Portsmouth, London \& Adelaide, 1834-1912', Typescript compiled by Geoffrey and Robert Clarke, Lt Ms. 7711, Box 640/3 (C), La Trobe Library, Melbourne.

Dredge, James, First Assistant Protector of the North Eastern District Protectorate Region, Diary, Ms 5244 Box 16/4, Latrobe Library, Melbourne.

Dredge, James, Letterbook, LT Ms 11625, Box 16/6, LaTrobe Library, Melbourne.

Historical Records of Australia (HRA) 1923, 1(XXI \& XXV), Government Printer, Sydney.

'LaTrobe Correspondence with GA Robinson, 1842-1848', LT Ms. 58431, Box 650/17, LaTrobe Library, Melbourne.

LaTrobe, Charles J 1841, 'Memoranda of Official Correspondence Port Philip 18391851', Manuscript Volume, Part 1, LT Ms Box 79/5, LaTrobe Library, Melbourne.

LeSouef, AAC 1895, 'Personal recollections of early Victoria' (typescript), ML A 2762, Mitchell Library, Sydney.

'Report of the Port Phillip District Committee of the Societies for Promoting Christian Knowledge and the Society for the Propagation of the Gospel', 1843, (Copy), ML A. 1291, Mitchell Library, Sydney.

GA Robinson Papers, ML A. 7075-2, Mitchell Library, Sydney.

Thomas Papers, [William Thomas], ML Box 7, Mitchell Library, Sydney.

Victorian Legislative Council Votes and Proceedings, 1853-1854(II). Government Printer, Melbourne.

\section{Secondary sources}

Abbie, AA 1969, The original Australians, Reed, Wellington.

Barwick, D 1976, 'The Aboriginal family in south-eastern Australia', The family in Australia: social, demographic and psychological aspects, ed J Krupinski and A Stoler, Pergamon Press, NSW: 195-209.

Berndt, RM and CH Berndt 1977, The world of the first Australians, Ure Smith, Sydney.

Berndt, RM, CH Berndt and J Stanton 1993, A world that was: the Yaraldi of the Murray River and lakes, South Australia, UBC Press, Vancouver. 
Beveridge, P 1889, The Aborigines of Victoria and Riverina as seen by Peter Beveridge, ML Hutchinson, Melbourne.

Birdsall, C 1987, 'Family history and social network among Nyungar people', Aboriginal History 11(2): 129-142.

Blainey G 1988, Triumph of the nomads: a history of ancient Australia, revised edition, Pan Macmillan, Chippendale.

Broome, R 1982, Aboriginal Australians: black response to white dominance 1788-1980, Allen and Unwin, Sydney.

Butlin, NG 1983, Our original aggression: Aboriginal populations of southeastern Australia 1788-1850, Allen and Unwin: Sydney.

Cannon, M 1990, Who killed the Koories? William Heinemann, Melbourne.

Cannon, M and I MacFarlane (eds) 1982, The Aborigines of Port Phillip, 1835-1839, Historical Records of Victoria, Foundation Series 2A, Victorian Government Printing Office, Melbourne.

1991, The Crown, the land and the squatter, 1835-1840, Historical Records of Victoria, Foundation Series 6, Melbourne University Press, Melbourne.

Clark, ID 1999, A history of the Goulburn River Protectorate Station at Murchison, 18401853, Report to the Heritage Services Branch, Aboriginal Affairs Victoria.

Clements, T 1947, From old Maloga, private publication, Shepparton Historical Society, Shepparton.

Cooper, A and L Blame (eds) 1981, Aunt Spencer's diary (1854): a visit to Bontharambo and the north-east Victorian goldfields. Neptune Press, Victoria

Critchett, J 1984, 'A closer look at cultural contact: some evidence from "Yambuk", western Victoria', Aboriginal History 8(1):12-20.

Curr, EM 1883, Recollections of squatting in Victoria: then called the Port Phillip District (from 1841 to 1851), George Robertson, Melbourne.

---- 1965 Recollections of squatting in Victoria: then called the Port Phillip District from 1841 to 1851), Abridged edition, Melbourne University Press, Melbourne.

----1886, The Australian race: its origins, languages, customs, place of landing in Australia and the route by which it spread itself over the continent, Vol 1, Government Printer, Melbourne.

Daylight, P and M Johnston 1986, Women's business: report of the Aboriginal Women's Task Force, Australian Government Publishing Service, Canberra.

Dredge, J 1845, Brief notices on the Aborigines of New South Wales, including Port Phillip, James Harrison, Geelong.

Ellis, CJ and L Barwick 1989, 'Antikirinja women's song knowledge 1963-72: its significance in Antikirinja culture', P Brock (ed),Women, rites and sites: Aboriginal women's cultural knowledge, Allen \& Unwin, Sydney: 21-40.

Hallam, S 1991, 'Aboriginal women as providers: the 1830s on the Swan', Aboriginal History 15(1): 38-53.

Hibbins, G 1978, A history of Nathalia Shire: the good helmsmen. Hawthorn Press, Melbourne.

Hinkins, JT 1884, Life among the native race: with extracts from a diary by the late John $T$ Hinkins, Haase, M'Queen \& Co, Melbourne. 
Jackomos, A and D Fowell (eds) 1991, Living Aboriginal history of Victoria: stories in the oral tradition, Cambridge University Press, Melbourne.

Lawlor, R 1991, Voices of the first day: awakening in the Aboriginal dreamtime, Inner Traditions International, Rochester.

McCombie, T 1845, Arabin, or, the adventures of a colonist in New South Wales, Simmonds \& Ward, London.

Matthews, RH 1905, Ethnological Notes on the Aboriginal Tribes of New South Wales and Victoria, FW White, Sydney.

Mitchell, Sir TL 1965, Three expeditions into the interior of eastern Australia: with descriptions of the recently explored region of Australia Felix, and the present colony of New South Wales, Vol 1, second edition (revised), Libraries Board of South Australia, Adelaide.

Morgan, M 2002, 'The Yorta Yorta Experience', Paper presented at The native title conference 2002: outcomes and possibilities, Plenary Session, 5 September 2002, Geraldton, Western Australia.

Parker, E S 1854, The Aborigines of Australia: a lecture delivered from the Mechanics Hall, Melbourne, before the John Knox Young Men's Association, on Wednesday, May 10th 1854, Hugh McColl, Melbourne.

Pitts, H 1914, The Australian Aboriginal and the Christian Church, Society for Promoting Christian Knowledge, London.

Reynolds, H 1982, The other side of the frontier: Aboriginal resistance to the European invasion of Australia, Penguin Books, Ringwood, Victoria.

Sturt, Mrs NG 1899, Life of Charles Sturt, sometime Capt. 39th Regiment and Australian explorer, Smith, Elder, London.

Taylor, DM 1999, 'Courage and compromise: an examination of the Aboriginal response to the European colonisation of north-eastern Victoria', Unpublished MA thesis, Monash University, Melbourne.

Thomson, D 1983, Children of the Dreamtime: traditional family life in Aboriginal Australia, Viking O'Neil, Ringwood.

Tilbrook, L 1986, 'A question of access: women, marriage and land ownership in southwestern Australia', Aboriginal History 10(2): 99-116.

Weiner, JF 2002, 'Diaspora, materialism, tradition: anthropological issues in the recent High Court Appeal of the Yorta Yorta', Land, Rights, Laws: Issues of Native Title, 2(19): 1-12. 